\title{
The role of turbulence in the hydraulic environment of benthic invertebrates
}

\author{
K. Blanckaert, ${ }^{1,2,3 *}$ X.-F. Garcia, ${ }^{2}$ A.-M. Ricardo, ${ }^{3,4}$ Q. Chen ${ }^{1}$ and M. T. Pusch $^{2}$ \\ ${ }^{1}$ State Key Laboratory of Urban and Regional Ecology, Research Center for Eco-Environmental Sciences (RCEES), Chinese Academy of Sciences \\ (CAS), Beijing, China \\ ${ }^{2}$ Department of Limnology of Shallow Lakes and Lowland Rivers, Leibniz-Institute of Freshwater Ecology and Inland Fisheries (IGB), Berlin, Germany \\ ${ }^{3}$ Laboratory of Hydraulic Constructions (LCH), Ecole Polytechnique Fédérale de Lausanne (EPFL), Lausanne, Switzerland \\ ${ }^{4}$ Instituto Superior Técnico, Lisbon, Portugal
}

\begin{abstract}
The role of turbulence in the dislodgment of benthic stream invertebrates from the riverbed was investigated experimentally in a laboratory flume. For the first time, technological advances allowed measuring the spatio-temporal patterns of turbulent flow around two free-moving invertebrates (Aeshna cyanea and Somatochlora flavomaculata). A specific methodology was developed for the analysis of turbulence around benthic invertebrates. The results confirmed two hypotheses: (i) on the contrary to sediment particles, invertebrates are not only sensitive to the peak values of the turbulent flow forcing but also to the temporal fluctuations in this flow forcing; and (ii) the dominant temporal fluctuations are not due to local turbulent structures of the size of the invertebrate, but to turbulent structures that scale with the flow depth and are inherited from upstream. In 15 of the 17 conducted tests, important turbulent events that scale with the flow depth accompanied by rapid temporal flow fluctuations occurred at the moment of dislodgement. The dominant forcing was consistently a threefold increase in shear stress, and was related to a sweep event in 12 of the 17 tests. Thereby, the increase in longitudinal velocity was typically about $40 \%$, which led to a 100\% increase in drag force in comparison with the time-averaged drag force. These results enable a new understanding of the detailed hydraulic conditions leading to passive drift of stream invertebrates. In addition, they open new perspectives to improve models predicting the distribution of benthic invertebrates based on hydrodynamics by accounting for turbulence. Copyright (C) 2012 John Wiley \& Sons, Ltd.
\end{abstract}

KEY WORDS turbulent coherent structure; invertebrate drift; invertebrate dislodgment; flume experiment; Odonata

Received 4 June 2012; Revised 4 July 2012; Accepted 5 July 2012

\section{INTRODUCTION}

Benthic invertebrates are key components of aquatic ecosystems, as they often occur in high densities and take a central position in aquatic food webs, linking microbiota and mesobiota with fish (Allan, 1995). Benthic invertebrates living on the streambeds of running waters have to cope with a relatively harsh hydraulic environment. They are exposed to flow, which may dislodge them from the streambed and force them to drift (Ambühl, 1959; Statzner and Holm, 1989; Statzner, 2008; Gibbins et al., 2010). Also, higher flow velocities may cause sediment movement and thus initiate invertebrate drift (Gibbins et al., 2007, 2010). The flow field near invertebrates has been identified as a dominant factor governing the spatial distribution of benthic invertebrates on streambeds (Statzner and Higler, 1986; Hart et al., 1996; Hart and Finelli, 1999; Reid and Thoms, 2008; Statzner, 2008; Oldmeadow et al., 2010; Long et al., 2011). However, even after more than a century of research, we do not fully understand what the relevant hydrodynamic forces acting on invertebrates are, which hampers the development of process-based models describing and quantifying the

*Correspondence to: Koen Blanckaert, State Key Laboratory of Urban and Regional Ecology, Research Center for Eco-Environmental Sciences, Chinese Academy of Sciences, Shuangqing Road 18, 100085 Beijing, China. E-mail: koen.blanckaert@epfl.ch physical-biological coupling in rivers. This inability can largely be attributed to the difficulty in adequately measuring flow conditions near living invertebrates (Hart and Finelli, 1999; Statzner, 2008).

The present paper focuses on the moment of passive dislodgement, i.e. the dislodgement of the benthic invertebrate from the riverbed caused by flow forces. Water flowing around a solid body, such as a sediment particle or an invertebrate, exerts shear and pressure stresses on that object. The integral of these stresses yields the total hydrodynamic force exerted by the flow, whereby the component in the flow direction is called the drag force, and the component perpendicular to it, the lift force (see Figure 1, Prandtl, 1930, 1942; Schlichting and Gersten, 2000).

Invertebrates on the streambed are located in the flow's boundary layer, i.e. the near-bed layer where the streambed's friction significantly reduces the flow velocity and causes a pronounced velocity gradient. The presence of an invertebrate body protruding into the bed boundary layer creates complex hydrodynamic patterns. The boundary layer concept was initially developed for flow over smooth surfaces, such as those found in pipes or on airplane wings. Very near smooth surfaces, a viscous sublayer exists where the flow is laminar. It has a thickness of $11.6 v / u_{*}$, where $v$ is the kinematic viscosity and $u_{*}$ the shear velocity on the bed (Einstein and Li, 1958; Schlichting and Gersten, 2000). Ambühl (1959) suggested that 

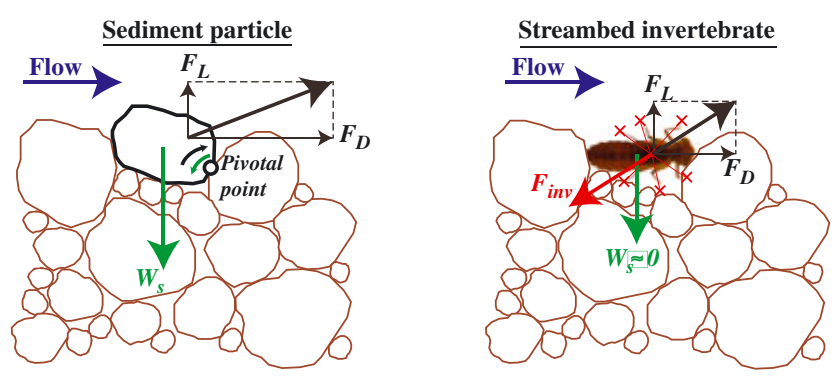

Figure 1. Schematic representation of the critical conditions for invertebrate dislodgment compared with the entrainment of a sediment particle. $W_{s}$ : submerged weight, $F_{L}$ and $F_{D}$ : lift and drag forces exerted by the turbulent flow, respectively and $F_{\text {inv }}$ : active resistance by the streambed invertebrate.

stream invertebrates are scarcely affected by the turbulent flow because they reside within the near-bed viscous sublayer that typically has a thickness of the millimetre order. These considerations omit the interaction between the invertebrate body and the bed boundary layer. Statzner and Holm (1982, 1989), for example, measured the separation of the boundary layer from the body of the invertebrate, which modifies the drag and the lift forces. Moreover, stream invertebrates do not live on smooth boundaries, but on rough and heterogeneous natural streambeds, where individual sediment particles protrude through the viscous sublayer (Sutherland, 1967; Grass, 1971; Raupach et al., 1981; Schlichting and Gerstens, 2000; Jimenez, 2004; Mignot et al., 2009). Under such conditions, the viscous sublayer is disrupted and turbulent flow structures extend onto the streambed. Nikora et al. (2001) have conceptualized hydraulically rough turbulent boundary layers in a spatially averaged model that subdivides the flow into several layers.

Turbulent flow structures are characterized by pronounced temporal flow fluctuations. Hart et al. (1996) have measured temporal velocity fluctuations at $2 \mathrm{~mm}$ above the streambed that vary by more than an order of magnitude. Associated accelerations of the flow occurred over a distance that is of the same order of magnitude than the body length of many macroinvertebrates. They found that the forces generated by these rapid temporal fluctuations are commonly larger than the time-averaged drag and lift forces. Recent advances in fluid mechanics (Robinson, 1991; Ashworth et al., 1996) have considerably enhanced the understanding of the organization of boundary layer turbulence into so-called turbulent coherent structures, as initially proposed by Batchelor (1970) and Grass (1971). The largest turbulent coherent structures are typically of the size of the flow depth. According to the energy cascade concept (Taylor, 1938; Hinze, 1959), they disintegrate and transfer their energy to ever-smaller structures. The turbulent energy is finally dissipated into heat by the smallest structures that are typically considerably smaller than the invertebrate body (Kolmogorov, 1961). These spatially coherent turbulence events occur only for a short fraction of time, but generate peak hydrodynamic forces (Antonia and Atkinson, 1973; Lu and Willmarth, 1973; Nakagawa and Nezu, 1977; Raupach et al., 1981; Robert, 1993; Nelson et al., 1995; Hurther et al., 2007).

The role of temporal flow fluctuations and turbulent coherent structures is assumed to be ecologically significant
(Eckman et al., 1990; Hart et al., 1996; Hart and Finelli, 1999; Statzner, 2008; Reid and Thoms, 2008; Oldmeadow et al., 2010), but remains poorly understood. This can largely be attributed to the difficulty in accurately measuring the pattern of turbulence near the invertebrate body. The investigations by Ambühl (1959) and Statzner and Holm $(1982,1989)$ were largely motivated by the evolutionary question of how stream invertebrates have adapted their shape in order to resist hydrodynamic forces. These investigations mainly focused on the local interactions between the invertebrate and the boundary layer. Statzner (2008) noted, however, that the local flow field cannot fully explain the flow adaptation of streambed invertebrates, because of the following: (i) the local flow field exerts different constraints during different life stages of the stream invertebrate; and (ii) the flow field around the invertebrates is intrinsically so complicated and so diverse (dependent on the invertebrate body shape and size, Reynolds number of the flow, boundary layer conditions), that it cannot be generalized. Similarly, Hart and Finelli (1999) already attributed the diversity and complexity of local flow fields to the unique arrangement of the sediment particles on the streambed. With the observed levels of turbulence that were greater than predicted from traditional boundary layer theory, Hart et al. (1996) also suggested that much of the turbulence is not produced by local shear, but inherited from upstream. These observations suggest that the dominant hydrodynamic force exerted on benthic invertebrates is not necessarily determined by local flow conditions.

The previously mentioned debate on the importance of temporal fluctuations and non-locally produced turbulent coherent structures concurs with Hart and Finelli (1999), who noted that flow characteristics in a stream vary over a broad range of space and time scales that can span more than six orders of magnitude, and who postulated that the identification of the most relevant scales is one of the central challenges in the study of organism-flow interactions.

Owing to limitations in measuring technology, previous investigations could only perform point-wise measurements, which only allowed visualizing spatial patterns of timeaveraged characteristics of the flow and the turbulence, but not of coherent turbulent structures. Moreover, the velocimeters did not allow tracking moving invertebrates. Hence, Statzner and Holm $(1982,1989)$ measured the flow around dead invertebrates glued on the streambed, whereas Hart et al. (1996), Lancaster et al. (2006), Oldmeadow et al. (2010), Schnauder et al. (2010) and Long et al. (2011) decoupled invertebrate observations and flow measurements, i.e. flow was measured at locations where invertebrates were previously observed. As a consequence, Hart and Finelli (1999), Statzner (2008) and Lancaster and Downes (2010) argued for the increased integration of concepts from fluid mechanics and the use of modern measurement technologies with high spatial, and particularly high temporal velocity resolution.

The experiments presented in this paper use an acoustic Doppler velocity profiler (ADVP) that has the ability to measure turbulent coherent structures with a high spatial and temporal resolution as well as to track moving invertebrates. The experiments aim to enhance insight in dominant hydrodynamic forces acting on streambed invertebrates, and 
focus on two hypotheses: (1) invertebrates are not only sensitive to the peak values of the turbulent flow forcing but also to the temporal fluctuations in this turbulent flow forcing, i.e. the time required for the flow forcing to fluctuate between its average and peak values; this constitutes a fundamental difference with respect to the passive transport of sediment particles that is only sensitive to the peak values; and (2) the dominant temporal fluctuations are not due to small-scale turbulent structures of the size of the invertebrate body that are influenced by the interaction between the boundary layer and the invertebrate body, but to large-scale turbulent structures that scale with the flow depth and are inherited from upstream.

Besides, the objectives of the paper are as follows: (i) to conceptualize the framework of analysis of turbulent flow fluctuations in ecological investigations on streambed invertebrates, which differs from its conceptualization in investigations on sediment transport; (ii) to identify and quantify the dominant turbulence characteristics as well as the temporal and spatial scales of relevance for invertebrates in controlled laboratory conditions to avoid interactions with other physical factors; and (iii) to discuss the potential of integration of these turbulence characteristics in models for physical-biological coupling.

\section{METHODS}

\section{Conceptual framework}

There are obvious resemblances, although also differences, between the dislodgement of sediment particles and invertebrates from the streambed. The hydrodynamic forces exerted by the flowing water on a sediment particle and on an invertebrate situated on the streambed are similar, and commonly represented by a drag force $\left(F_{D}\right)$ in the flow direction and a lift force $\left(F_{L}\right)$ perpendicular to it (Figure 1):

$$
\begin{aligned}
& F_{D}=C_{D} S \frac{1}{2} \rho v_{\text {bed }}^{2} \\
& F_{L}=C_{L} S \frac{1}{2} \rho v_{\text {bed }}^{2}
\end{aligned}
$$

where $C_{D}$ and $C_{L}$ are drag and lift coefficients, respectively, $S$ is the area of the projection perpendicular to the flow of the sediment particle or the invertebrate body, $\rho$ is the water density and $v_{\text {bed }}$ is the near-bed velocity.

However, the forces that resist the dislodgement of a sediment particle and an invertebrate are fundamentally different. The submerged weight $W_{s}$ of sediment particles is the main force that opposes dislodgement from the bed because their density (about $2650 \mathrm{~kg} \mathrm{~m}^{-3}$ ) is much higher than that of water. The submerged weight of particles is constant and independent of the flow conditions. The sediment particles are dislodged from the bed when the destabilizing moment created by the hydrodynamic forces around the pivotal point exceeds the stabilizing moment created by the submerged weight (Figure 1). Hence, dislodgement is merely determined by the static equilibrium of forces, where inertia and temporal fluctuations do not play an essential role. Obviously, the relevant hydrodynamic forces for the dislodgment of the particle are those generated during peak turbulent events.

On the contrary, the submerged weight of invertebrates is negligible (their density is close to the water density $1000 \mathrm{~kg} \mathrm{~m}^{-3}$ ) and has no significant influence on the dislodgement. Streambed invertebrates mainly lower their dislodgement risk by various morphological and behavioural traits (Hynes, 1970; Koehl, 1984, 1996; Weissenberger et al., 1991; Vogel, 1994; Hart and Finelli, 1999), such as a flat body shape, anti-streamwise orientation, active search for zones of reduced forcing on the heterogeneous sediment bed, and fixing strategies $\left(F_{\text {inv }}\right.$ in Figure 1). Our first hypothesis expresses that invertebrates may be able to resist high turbulent peak values in the flow forcing, but are sensible to temporal fluctuations in the flow forcing.

Turbulence is known to be important with respect to the dislodgement of invertebrates (Eckman et al., 1990; Hart et al., 1996), but its effects are difficult to incorporate in conceptual models because of its intrinsically stochastic nature. Shields (1936) developed his commonly used critical shear stress for the dislodgement of sediment particles based on a static force balance, where he estimated the drag and lift forces from the time-averaged flow field. Statzner et al. (1988) and Schnauder et al. (2010) similarly proposed timeaveraged flow characterizations for the dislodgement of different invertebrate species. Obviously, time-averaged values and turbulent peak values are related, i.e. the higher the time-averaged values of a varying factor, the higher also its extreme turbulent values and the associate temporal fluctuations. Time-averaged approaches can therefore give satisfactory results in simple flow fields because similarity relationships exist, which quantify the relation between timeaveraged flow characteristics and turbulence (Nezu and Nakagawa, 1993). But these time-averaged approaches fail in more complicated three-dimensional flow fields as found in natural rivers, where the relations between time-averaged and peak values can no longer be quantified by means of simple relations. Escauriaza and Sotiropoulos (2011) and Chang et al. (2012) illustrate this limitation of time-averaged approaches for the case of junction flows and flows behind obstacles, respectively.

It is relatively straightforward to account for the effect of turbulence on the dislodgement of sediment particles, by basing the static force balance on the peak magnitudes of velocity and shear stress instead of the time-averaged values. Similarly, the transport of sediment particles can be based on the instantaneous magnitudes of velocity and shear stress instead of the time-averaged values (van Prooijen and Winterwerp, 2010; Chang et al., 2012). The latter have successfully applied this approach to compute numerically the dislodgement and transport of sediment particles by the three-dimensional flow behind an in-stream obstacle. Regarding living organisms, no study has been published yet that tries to account for the effect of turbulence on invertebrate dislodgement because the relevant temporal and spatial scales of the turbulent fluctuations and their parameterization have so far remained unknown. To analyse these relevant scales, we propose to decompose the measured 
hydrodynamic patterns into a time-averaged value and temporal deviations from that time-averaged value $(i, j=x, y, z)$ :

$$
\begin{gathered}
v_{i}=\overline{v_{i}}+v_{i}^{\prime} \\
v_{i}^{\prime} v_{j}^{\prime}=\overline{v_{i}^{\prime} v_{j}^{\prime}}+\left(v_{i}^{\prime} v_{j}^{\prime}-\overline{v_{i}^{\prime} v_{j}^{\prime}}\right) \\
t k e=\overline{t k e}+t k e^{\prime} \\
t k e=0.5\left(v_{x}^{\prime 2}+v_{y}^{\prime 2}+v_{z}^{\prime 2}\right) \\
F_{D, L}=\overline{F_{D, L}}+F_{D, L}^{\prime}
\end{gathered}
$$

Here $v_{x}, v_{y}$ and $v_{z}$ are the velocity components in the streamwise, transverse and vertical directions, primes symbolize temporal velocity fluctuations and the overbar symbolizes time averaging. The turbulent shear stresses are represented by $v_{i}^{\prime} v_{j}^{\prime}$, and the turbulent kinetic energy by tke as defined by Equation (6). Whereas the decomposition of the velocity components [Equation (3)] is a common practice in fluid dynamics, the decomposition of turbulent quantities [Equations (4) and (5)] constitutes an adapted conceptualization for the ecological context. Translated into physical terms, it expresses our first hypothesis that streambed invertebrates can resist high time-averaged turbulence, but are vulnerable to temporal fluctuations in turbulence. Our measurements and analyses therefore focused on the temporal fluctuations of these characteristics of flow and turbulence. Additionally, we studied the spatial-temporal patterns of the turbulent fluctuations in order to analyse the dominant spatial scales of turbulence.

\section{Studied organisms}

Experiments were conducted with larvae of two free-living dragonfly (Odonata) species Aeshna cyanea (Müller, 1764) and Somatochlora flavomaculata (van der Linden, 1825) (Figure 2). Specimens were collected in the lowland River Spree, south-east of Berlin (NE Germany), at the margin of a riffle reach. The next day, they were transported in aquariums filled with water and leaf litter from their original habitat to the Laboratory of Hydraulic Constructions (EPFL, Switzerland) where the experiments took place. At the laboratory, the individuals were kept in aquariums filled with oxygen saturated water from the experimental flume and leaf litter from their original habitat. Flume water consisted in tap water saturated in oxygen, maintained at a constant temperature of $18^{\circ} \mathrm{C}$. The water was pumped from a $700 \mathrm{~m}^{3}$ aerated basin into the flume and subsequently returned to the basin. The

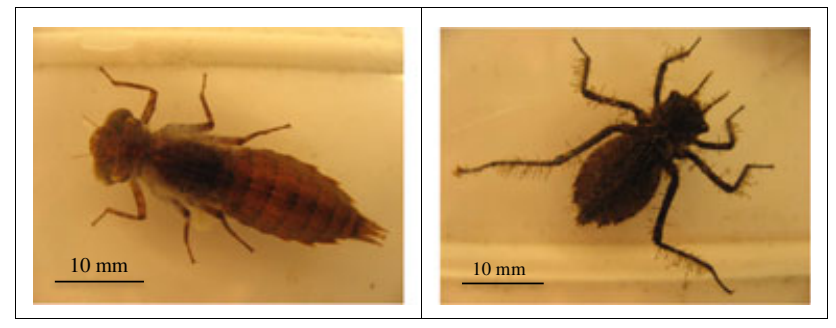

Figure 2. Investigated species: Larvae of Aeshna cyanea (left) and Somatochlora flavomaculata (right) (Odonata Anisoptera). basin water is regularly refreshed and mixed with 251 of $13 \%$ hypochlorite, resulting in an initial mass concentration of sodium hypochlorite of the order $1 \mathrm{ppm}$, which is sufficiently low not to cause any stress for living organisms (Anasco et al., 2008). To avoid the influence of stress due to transportation and let the larvae accustom to flume water, the transfer from original habitat water to flume water was made over $24 \mathrm{~h}$, in several steps consisting of mixing the two water types. Specimens were then kept for 2 days in the aquarium before starting the experiments. Larvae were fed ad libitum with living red worms (Chironomidae and Tubificidae) during transport and between experiments.

The 'Southern Hawker' A. cyanea is a European-wide distributed species found in the littoral zones of lakes and rivers (Janecek et al., 1995; Schmedtje and Colling, 1996). Larvae are known to preferentially colonize macrophyte patches or sediments enriched with fine organic material. They are predators mainly walking, but also actively swimming (Schmedtje and Colling, 1996). The larvae are characterized by short robust legs and flat elongated body shapes. Body lengths of the two collected specimens used in the experiments were 2.6 and $2.8 \mathrm{~cm}$, respectively.

The 'Yellow-Spotted Emerald' S. flavomaculata specimens also inhabit littoral zones of rivers. They are preferentially found in the metapotamal sections of the rivers (Janecek et al., 1995), where they colonize silted sediment beds. Larvae mainly hunt while they are burrowed into the soft sediment (Schmedtje and Colling, 1996). They are relatively poor swimmers, and mainly move by walking on the streambed. The larvae have long legs that are used to burrow into the sediment and a flat, stubby body (Figure 2). The body length of the single collected specimen used in the experiment was $2.0 \mathrm{~cm}$.

\section{Experimental set-up}

Experimental flume. The experimental facility consisted of an $8.5 \mathrm{~m}$ long, $0.5 \mathrm{~m}$ wide laboratory flume with smooth vertical walls, allowing a maximum depth of $0.24 \mathrm{~m}$. At $3.6 \mathrm{~m}$ downstream of the flume inlet, a $0.15 \mathrm{~m}$ wide tributary channel joined the main channel at an angle of $90^{\circ}$ (Figure 3 ). The heterogeneous bed surface material and bathymetry were obtained in a preliminary experiment (Leite Ribeiro et al., 2012) and resulted from supplying a flow discharge of $181 \mathrm{~s}^{-1}$ and $21 \mathrm{~s}^{-1}$ in the main and tributary channels, respectively, and a sediment load of $0.3 \mathrm{~kg} \mathrm{~min}^{-1}$ uniquely in the tributary channel. The poorly sorted sediment was characterized by $d_{50}=0.8 \mathrm{~mm}, d_{\mathrm{m}}=2.3 \mathrm{~mm} d_{90}=5.7 \mathrm{~mm}$ and a sorting coefficient of $\sigma=0.5\left(d_{84} / d_{50}+d_{50} / d_{16}\right)=4 \cdot 15$. Here, $d_{\mathrm{m}}$ is the mean diameter of the sediment and $d_{j}$ is the $j$ percentile value of the grain size distribution. This procedure led to the armoring of the channel bed upstream of the tributary channel and the development of a bar of coarse sediment just downstream of the confluence [Figure 3(c)]. No sediment was supplied during experiments on invertebrate dislodgement.

Measuring instruments. Non-intrusive measurements of velocity profiles were performed with an ADVP developed at EPFL (See Lemmin and Rolland, 1997; Hurther and 


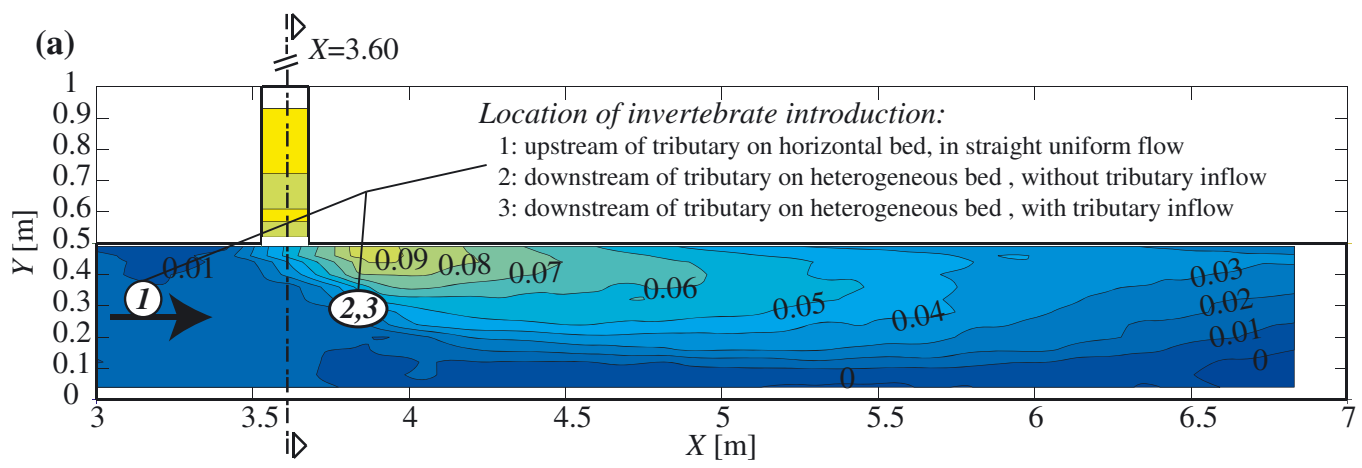

(b)

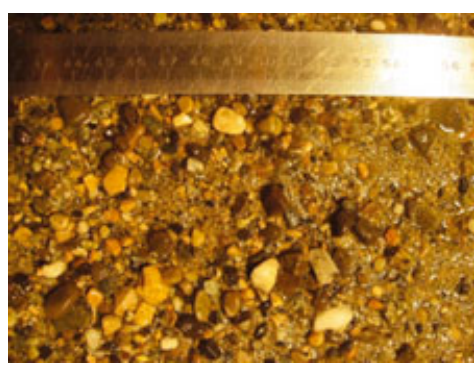

(c)

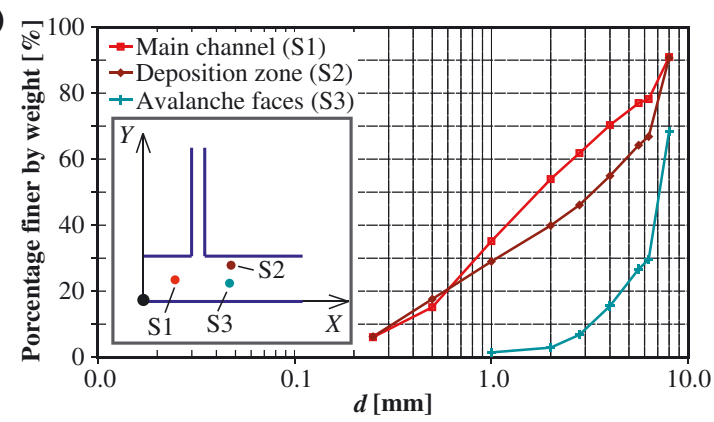

Figure 3. (a) Schematic representation of the laboratory flume including the main channel, the tributary channel, and the three different locations where tests on invertebrate dislodgment were performed. The contours and colour code represent the bathymetry. (b) Spatial heterogeneity of the bed surface material in the reach upstream of the confluence. (c) Sieving curves of the bed surface material at different locations in the flume.

Lemmin, 1998; Blanckaert and Graf, 2001; Blanckaert and Lemmin, 2006 for the working principle of the ADVP, and Blanckaert and de Vriend, 2004; Blanckaert, 2010 for data treatment procedures and measurement accuracy). This velocimeter consists of a central emitter, surrounded by four receivers, placed in a water-filled box that touches the water surface by means of an acoustically transparent mylar film (Figure 4). It measures the quasi-instantaneous

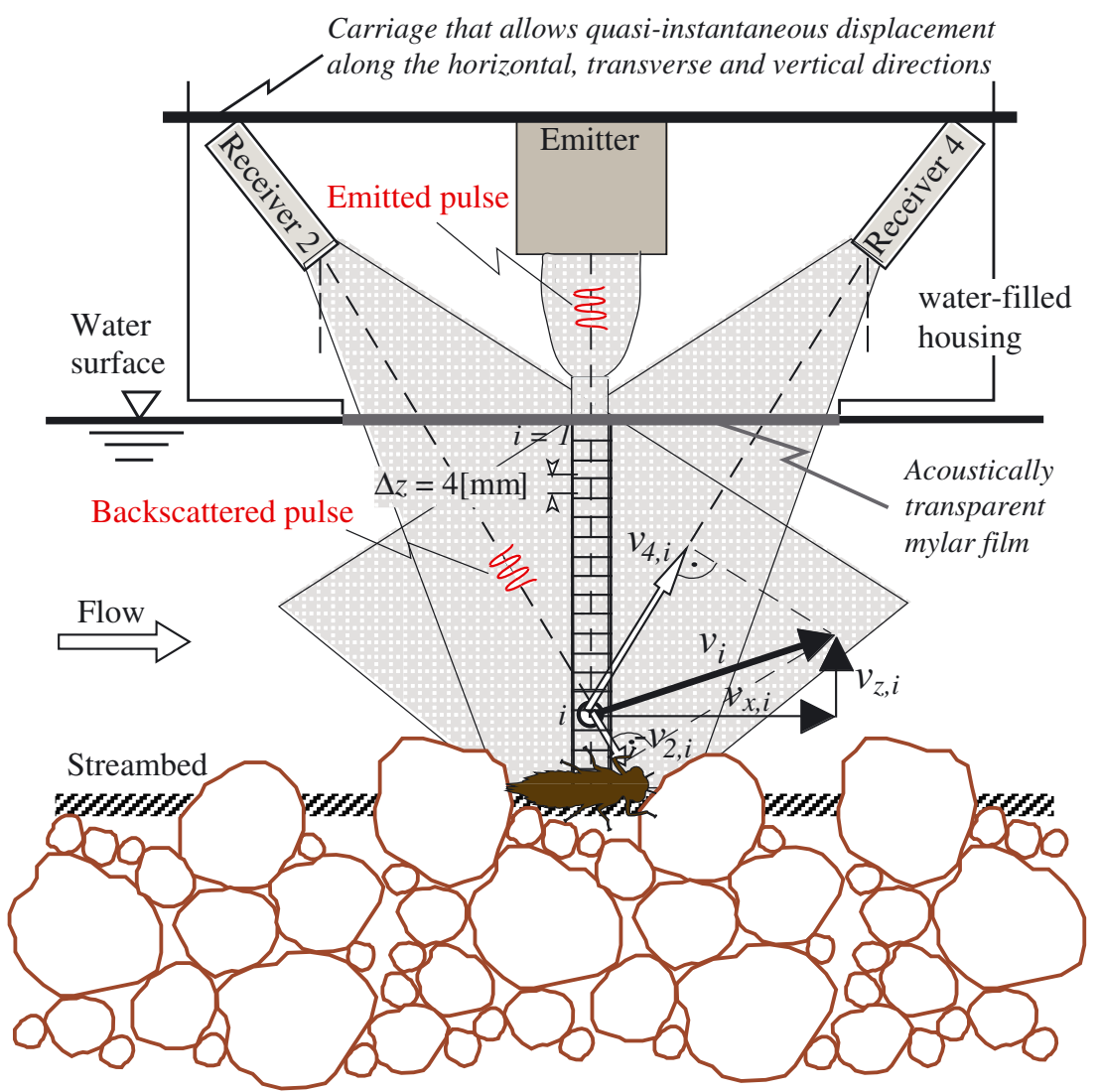

Figure 4. Schematic representation of the acoustic Doppler velocity profiler (ADVP). Only two of the four receivers are drawn. Modified from Blanckaert and Lemmin (2006). 
velocity vector, $\vec{v}(t)=\left(v_{x}, v_{y}, v_{z}\right)(t)$, simultaneously in an entire vertical water column that ranges from the water surface to the streambed, from which all relevant hydrodynamic characteristics can be computed [Equations (3)-(7)]. The vertical water column situated above the invertebrate (Figure 4) was measured with a sampling frequency of $31.25 \mathrm{~Hz}$. The measured water column was divided into bins with a height of $4 \mathrm{~mm}$ (Figure 4). This profiling capacity is a crucial methodological progress as compared with velocimeters used in previous studies that only measured the velocity in one single point (LDA in Statzner and Holm, 1982, 1989; hot-film in Hart et al., 1996; ADV in McReid and Thoms, 2008; Oldmeadow et al., 2010). The profiling capacity allows visualizing the flow patterns with high spatial resolution, and thus may especially show turbulent coherent structures occurring in the vicinity of the invertebrate. The ADVP was mounted on a carriage that allows its quasiinstantaneous displacement along the horizontal, transverse and vertical directions (Figure 4). This allowed the ADVP to follow the movement of the invertebrate on the streambed, which is another important progress as compared with velocimeters used in previous studies.

In order to accurately detect the moment of invertebrate dislodgment, ADVP velocity measurements were synchronized with a video acquisition of the invertebrate movement at a frequency of $5 \mathrm{~Hz}$. Hence, the moment of invertebrate dislodgment could be determined with a precision of $\pm 0 \cdot 1 \mathrm{~s}$.

\section{Experimental design}

Three different hydraulic conditions were investigated to cover the high variability inherent in turbulent flow (Figure 3a). In the first, the invertebrate was introduced upstream of the confluence where the bed is flat and the flow quasi uniform. In the second, the invertebrate was introduced in the confluence zone, where important gradients existed in bathymetry, streambed surface material and flow characteristics. In the third, the invertebrate was also introduced in the confluence zone, but an additional discharge was provided by the tributary in order to modify local flow characteristics.

Invertebrate specimens were introduced on the streambed under quasi-stagnant flow conditions (Figure 5) and were given $5 \mathrm{~min}$ to become accustomed to the slowly flowing water and flume environment. The flow was then gradually increased until it attained hydraulic conditions that trigger invertebrate dislodgment (Figure 5). These critical conditions for invertebrate dislodgment had been estimated in preliminary experiments to avoid tiredness of invertebrates caused by very long exposure to flow. The flow (discharge and depth) was then maintained constant at a period that encompasses the dislodgment moment (Figure 5).

Experiments were replicated three to six times for each hydraulic condition with larvae of $A$. cyanea and once for each hydraulic condition with larvae of S. flavomaculata, resulting in a total of 17 conducted tests. Such number of tests corresponds to the number of repetitions used by Lancaster et al. (2006), Oldmeadow et al. (2010) and Long et al. (2011) in laboratory experiments on invertebrate hydraulics. The larvae were given at least $2 \mathrm{~h}$ of recovery between two experiments.

\section{Data treatment and analysis}

The methodology used for data treatment and the experimental analysis is illustrated by means of test 1 (cf. Table 1 ).

Time-averaged flow characteristics. The characteristics of flow are commonly parameterized by the time-averaged longitudinal velocity $\overline{v_{x}}$, longitudinal-vertical shear stress $\overline{v_{x}^{\prime} v_{z}^{\prime}}$ and turbulent kinetic energy, $\overline{t k e}$. Movement of the invertebrate required the displacement of the ADVP, which induced perturbations in the velocity measurements (Figure 5). To obtain reliable estimates of the timeaveraged flow characteristics at invertebrate dislodgement, the longest possible time window that was free of such perturbations was determined. This determination was based on the measured longitudinal velocity, which has been averaged over the central part of the water column $(0.25<z / h<0.75$, where $h$ is flow depth) to minimize the fluctuations caused by turbulence (Figure 5). This time window free of perturbations was on the average $33.9 \mathrm{~s} \mathrm{long}$. It varied considerably between experiments, with a minimum duration of $7.6 \mathrm{~s}$, a maximum duration of $94.6 \mathrm{~s}$ and a standard deviation of $24.5 \mathrm{~s}$. We postulate that invertebrate dislodgment is mainly determined by local flow characteristics around the invertebrate specimen. Therefore, Figure 5 also illustrates the temporal dynamics of the longitudinal velocity averaged in the zone of $0-1.6 \mathrm{~cm}$ height above the bed. This vertical position has been chosen because it is near the top elevation of the invertebrate body of the two species

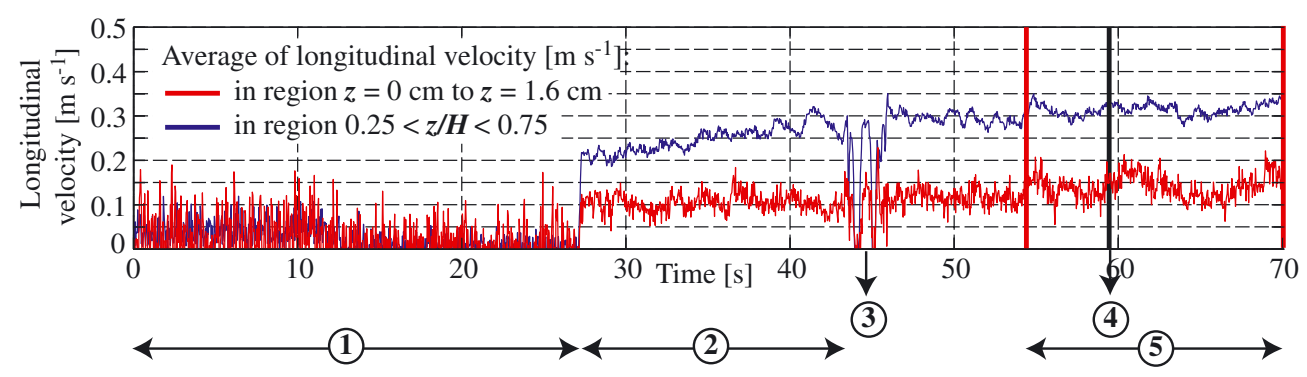

Figure 5. Experimental design illustrated with the temporal dynamics of measured longitudinal velocity (example of test 1, see Table 1). (1) Introduction of the invertebrate under quasi-stagnant flow conditions; (2) gradual increase of flow until conditions that trigger invertebrate dislodgment; (3) displacement of the acoustic Doppler velocity profiler to follow invertebrate movement, inducing a perturbation in the velocity signal; (4) dislodgment moment identified from synchronized video acquisition; and (5) longest time window of constant flow conditions used to estimate the time-averaged flow characteristics. 


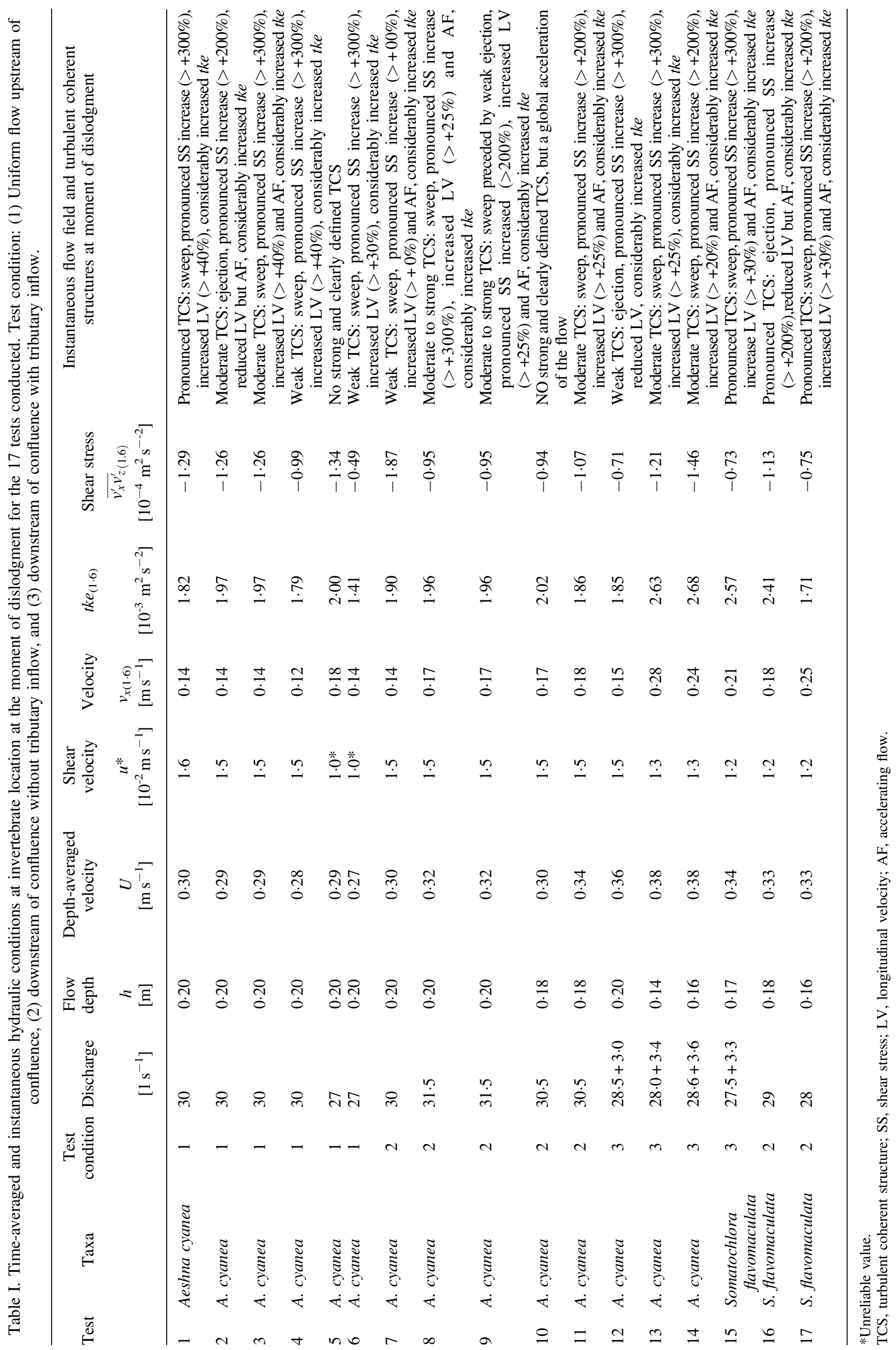



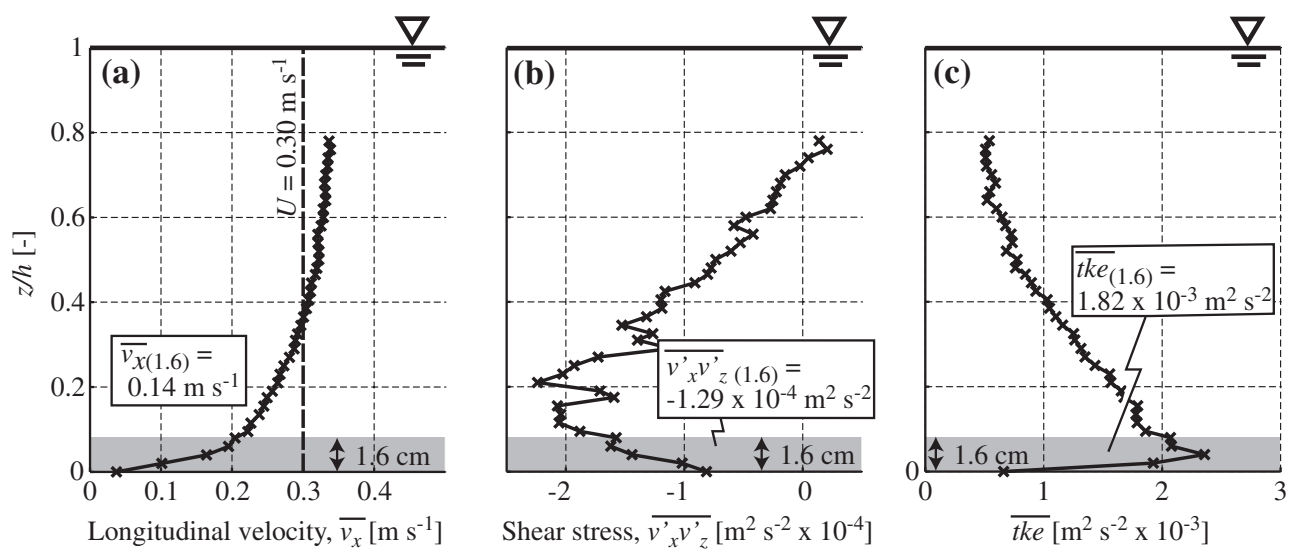

Figure 6. Vertical profiles of time-averaged flow quantities estimated from measurements in the longest time window with constant flow conditions corresponding to dislodgment (Figure 5). (a) Longitudinal velocity; (b) longitudinal-vertical turbulent shear stress; and (c) turbulent kinetic energy. Averaged values of the flow characteristics in the $0-1.6 \mathrm{~cm}$ height zone above the bed are indicated in boxes. Measurements close to the water surface were not reliable because of the local flow perturbation induced by the acoustic Doppler velocity profiler instrument that touches the water surface.

considered. Figure 6 shows the vertical profiles of the three considered time-averaged flow variables measured at the critical conditions for dislodgment in test 1 , as well as the corresponding values averaged in the zone of $1.6 \mathrm{~cm}$ height above the bed. The measured profiles are rather smooth, which is indicative of the good quality and accuracy of the measurements, in spite of the relatively short unperturbed time window in this test of $15.7 \mathrm{~s}$. The mean shear stress on the bed $\tau_{b}=\rho u_{*}^{2}$, is also expected to play a dominant role in invertebrate dislodgment. It has been estimated according to the method proposed by Nezu and Nakagawa (1993) by fitting logarithmic, linear and exponential functions to the lower part of the measured profiles of longitudinal velocity, shear stress, and $t \bar{k} e$, respectively.

Instantaneous flow characteristics. Figure 7 illustrates the spatial-temporal patterns of some turbulence quantities in a time window that extends from $2 \mathrm{~s}$ before dislodgment to $1 \mathrm{~s}$ after dislodgment. The dislodgment moment is indicated by the dashed vertical line, which means that the invertebrate has experienced all flow structures located to the right of this line in the $2 \mathrm{~s}$ before dislodgment. The vectors in all figures represent the longitudinal-vertical velocity fluctuations. Integration in time (i.e. along the horizontal axis in the figure) of these vector patterns would yield the time-averaged longitudinal-vertical shear stress profile shown in Figure 6(b). According to Taylor's hypothesis of frozen turbulence (Taylor, 1938), turbulent coherent structures only evolve slowly while being advected by the flow at a speed corresponding to the depth-averaged velocity $U$. This means that the time $t$ in Figure 7 can be converted in a distance $x=-U t$, and that the figures can be interpreted as snapshots of the spatial patterns of the turbulence at the dislodgment moment.

The colour patterns in Figure 7(a) represent turbulent coherent structures identified by means of a classical quadrant analysis of the longitudinal-vertical shear stress, as originally proposed by Lu and Willmarth (1973). Such an analysis is commonly used to investigate the relationship between turbulence coherent structures and the ejection of sediment into suspension (e.g. Sutherland,
1967; Nezu and Nakagawa, 1993; Hurther and Lemmin, 2003; Cellio and Lemmin, 2004; Dwivedi et al., 2011), which suggests its appropriateness to investigate invertebrate dislodgment. This quadrant analysis is illustrated in Figure 8 for a zone of $1.6 \mathrm{~cm}$ above the bed. This is an alternative representation of the same longitudinal-vertical velocity fluctuations shown by means of the vector patterns near the streambed in Figure 7. Because the time-averaged shear stress is negative [Figure 6(b)], negative contributions in the second and fourth quadrants outweigh positive contributions in the first and third quadrants. Quadrant two events are called ejections and correspond to a deceleration of the longitudinal flow component associated with uplift; quadrant four events are called sweeps and correspond to an acceleration of the longitudinal flow associated with vertical velocities directed towards the streambed (Kline et al., 1967). The quadrant analysis allows identifying important longitudinal-vertical velocity fluctuations that occur only during a short fraction of the total time, but may constitute the dominant events with respect to sediment transport or invertebrate dislodgment. Values that are found outside the red hyperbolic lines in Figure 8 correspond to quasi-instantaneous shear stresses that are larger than the time averaged bed shear stress: $\left|v_{x}^{\prime} v_{z}^{\prime}\right|>u_{*}^{2}$. These important quasi-instantaneous shear stresses occur in the form of spatially coherent structures. Figure 7(a) visualizes these spatially coherent turbulent structures corresponding to the first, second, third and fourth quadrants with zones coloured in blue, green, yellow and red, respectively. The figure shows that an important sweep event occurs near the bed at dislodgment in the illustrated test 1 .

The colour patterns in Figure 7(b) represent the fluctuations of the longitudinal-vertical shear stress around its timeaveraged value, according to Equation (4). This timeaveraged value corresponds to the vertical profiles shown in Figure 6(b). High amplitudes of the longitudinal-vertical shear stress fluctuations also occur in spatially coherent patterns, which are related to the patterns identified by the quadrant analysis. In the illustrated test 1 , a zone of very high shear stress occurs near the bed at the moment of dislodgment, with a peak amplitude of the fluctuation that is about $300 \%$ 


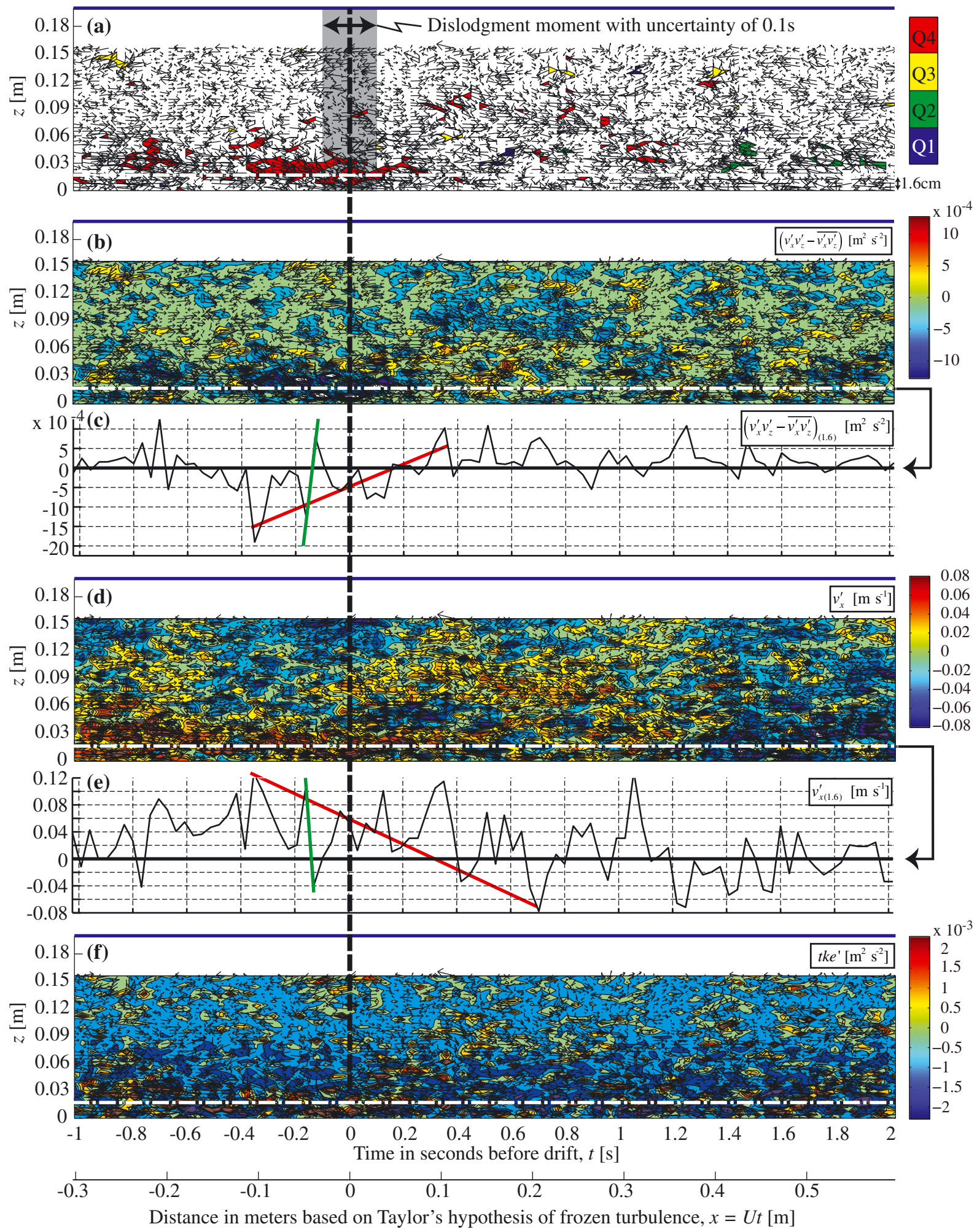

Figure 7. Patterns of some turbulence quantities measured (example of test 1) during a time window that extends from $2 \mathrm{~s}$ before invertebrate dislodgment to $1 \mathrm{~s}$ after dislodgment. The vectors in the plots (a), (b), (d) and (f) represent the longitudinal-vertical velocity fluctuations $v_{x}^{\prime} v_{z}^{\prime}$, represented with a vertical spatial resolution of $4 \mathrm{~mm}$ and a temporal resolution of $31.25 \mathrm{~Hz}$. The colour plots represent patterns of the following: (a) A quadrant analysis of the longitudinal-vertical velocity fluctuations. The coloured zones are characterized by quasi-instantaneous shear stresses that are larger in magnitude than the time-averaged bed shear stress, $\left|v_{x}^{\prime} v_{z}^{\prime}\right|>u_{*}^{2}$ (Figure 8). Each colour represents one quadrant as indicated in Figure 8. (b) Deviations of the quasi-instantaneous longitudinal-vertical turbulent shear stress from its time-averaged value, $v_{x}^{\prime} v_{z}^{\prime}-\overline{v_{x}^{\prime} v_{z}^{\prime}}$ [Equation (4)]. (d) Longitudinal velocity fluctuations, $v_{x}^{\prime}$. (f) Deviations of the turbulent kinetic energy from its time-averaged value, $t k e$ ' [Equation(5)]. The line plots show the temporal evolution at $1.6 \mathrm{~cm}$ above the bed of the following: (c) Deviations of the quasi-instantaneous longitudinal-vertical turbulent shear stress from its timeaveraged value, $v_{x}^{\prime} v_{z}^{\prime}-\overline{v_{x}^{\prime} v_{z}^{\prime}}$. (e) Longitudinal velocity fluctuations, $v_{x}^{\prime}$. The scaling of the axis is chosen such that coherent turbulent structures are undistorted in space. The vertical dashed line indicates the dislodgment moment identified from the video imaging. The horizontal dashed white line delimits the zone of $1.6 \mathrm{~cm}$ near the bed, which is highlighted in the analysis. 
Total time-averaged turbulent shear stress:

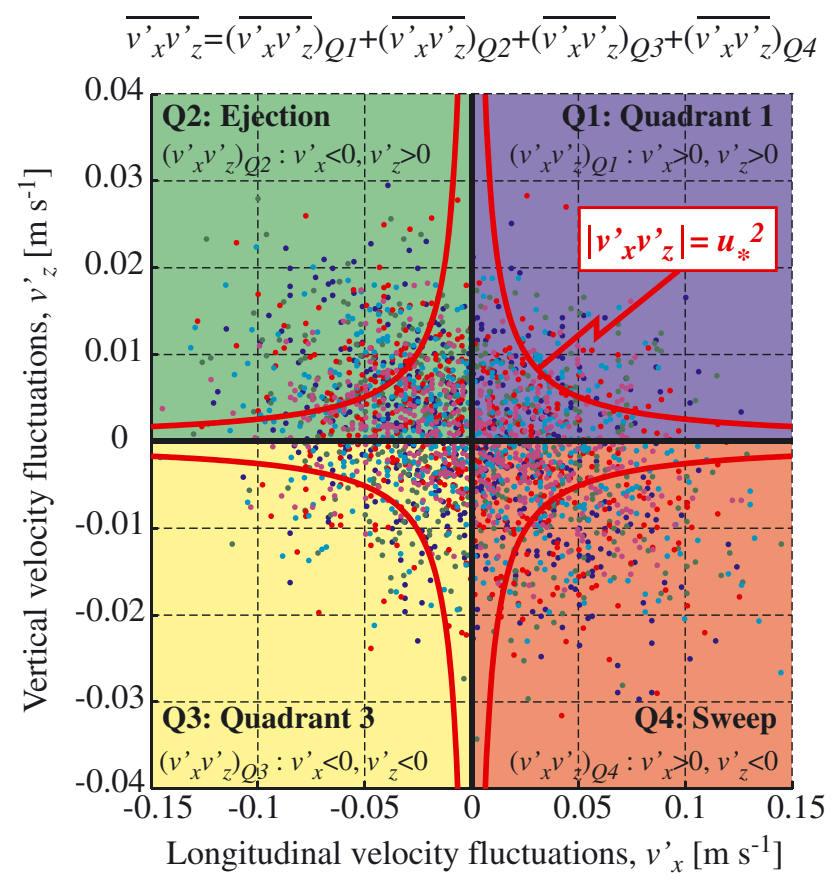

Figure 8. Quadrant representation of the longitudinal-vertical velocity fluctuations measured in a zone of $0-1.6 \mathrm{~cm}$ height above the flume bed (example of test 1). Points situated outside the red hyperbolic lines represent quasi-instantaneous shear stresses that are larger than the timeaveraged bed shear stress. Turbulence events corresponding to these points are highlighted in Figure 7(a).

larger than the time-averaged shear stress [Figure 7(b)]. According to Equation (4), this means that the peak value of the shear stress is about four times higher than the timeaveraged value.

The colour patterns in Figure 7(c) represent the fluctuations of the longitudinal velocity component, $v_{x}{ }^{\prime}$, around its timeaveraged value [Equation (3)] shown in Figure 6(a). In test 1, dislodgment occurs during a turbulent event characterized by longitudinal near-bed velocities that are substantially $(+40 \%)$ higher than the time-averaged value. This implies a considerable increase in drag and lift forces on the invertebrate, which scale with the square of the near-bed velocity [Equations (1) and (2)].

The colour patterns in Figure 7(d) represent the fluctuations of the tke around its time-averaged value [Equation (5)] shown in Figure 6(c). In test 1, a considerable increase in tke is observed at the dislodgment moment. Such an increase in tke is mainly felt as a pressure fluctuation by the invertebrate.

\section{RESULTS}

At the moment of dislodgement of the invertebrate specimen, flow variables varied within only a relatively restricted range: flow depth $h$ varied between 0.14 and $0.20 \mathrm{~m}$, discharge $Q$ between 27 and $321 \mathrm{~s}^{-1}$, depth-averaged velocity $U$ between 0.27 and $0.38 \mathrm{~m} \mathrm{~s}^{-1}$, and shear velocity $u *$ between 0.012 and $0 \cdot 016 \mathrm{~m} \mathrm{~s}^{-1}$ (Table 1). The particle Reynolds number in all experiments was larger than $70, R e_{*}=u * k_{s} / v$ (where $v$ is the kinematic viscosity and $k_{s}$ the equivalent sand roughness, which was estimated as $k_{s}=3 d_{90}$ according to van Rijn, 1984). Hence, flow exhibited a rough turbulent flow regime, which is a characteristic of natural rivers.

Time-averaged values of the bed shear stress $\tau_{b}=\rho u_{*}^{2}$, as well as the time-averaged values of longitudinal velocity, longitudinal-vertical shear stress and $t \bar{k} e$ in a zone of $0-1.6 \mathrm{~cm}$ above the invertebrate also varied within only a relatively restricted range, in spite of the three different investigated flow conditions (Table 1). This confirms that the invertebrate dislodgement primarily depends on the flow characteristics in the immediate vicinity of the invertebrate. Moreover, low variability proves the good reproducibility of the tests.

In 15 out of the 17 tests, important turbulent events occurred at the dislodgment moment that left a footprint on the quadrant distribution of the longitudinal-vertical shear stress, longitudinal velocity fluctuations and tke (Table 1). The dominant hydraulic forcing at the moment of dislodgment was related to the pronounced increase of the shear stress on the invertebrate, which reached peak values that were typically about $300 \%$ higher than the timeaveraged value. This strong increase in shear stress was related to a sweep event in 12 of the tests, and to an ejection event in three of the tests (Table 1). Sweep events are by definition characterized by an increased longitudinal velocity, which leads to increased lift and drag forces on the invertebrate. The peak increase in longitudinal near-bed velocity was typically about $40 \%$, which leads to an increase of about $100 \%$ in the drag force [Equation (1)] with respect to the time-averaged drag force. During ejection events, the drag force was reduced, but an upward velocity fluctuation occurred that increased the lift force and promoted dislodgment. These turbulence events at dislodgment were typically accompanied by an increase in tke, which was, however, smaller in magnitude and less spatially coherent.

The results furthermore showed that the turbulence variables considered fluctuated significantly in time and especially increased rather abruptly towards their peak values at dislodgment, which concurs with our first hypothesis. The examples for test 1 in Figure 7(c) and (e) clearly illustrate the two investigated working hypotheses and the occurrence of temporal fluctuations at different characteristic scales, which correspond to the organization of the boundary layer into turbulent coherent structures of different sizes. The green lines in Figure 7(c) and (e) correspond to small-scale rapid fluctuations at $1.6 \mathrm{~cm}$ above the streambed, which are of the order of $3 \mathrm{~m} \mathrm{~s}^{-2}$ for longitudinal velocity [Figure 7(c)], and of $0.03 \mathrm{~m}^{2} \mathrm{~s}^{-3}$ for longitudinal-vertical shear stress [Figure 7(e)]. Expressed in more physical terms, this corresponds to changes in the longitudinal velocity with an amplitude of $u *$ within $0.005 \mathrm{~s}$, and changes in the longitudinal-vertical shear stress with an amplitude of $u_{*}^{2}$ within $0.009 \mathrm{~s}$. These changes occurred over a distance $(x=-U t)$ that is comparable with the body size of the invertebrate [Figure 7(c) and (e)]. Hart et al. (1996) measured fine-scale rapid velocity fluctuations of 
similar magnitude $\left(8 \mathrm{~m} \mathrm{~s}^{-2}\right)$ that were also of the size of the invertebrate, and hypothesized that they represent a dominant flow forcing on the streambed invertebrates.

The peak values occurring in 15 out of the 17 tests at the dislodgment moment were not related to these fine-scale rapid fluctuations, but generated by spatially coherent turbulent structures that scale with flow depth (Figure 7). They led to larger scale velocity fluctuations that are represented by the red lines in Figure 7(c) and (e). These turbulent coherent structure induced changes in the longitudinal velocity of about $0.2 \mathrm{~m} \mathrm{~s}^{-2}$ [Figure 7(c)], which correspond to changes with an amplitude of $u_{*}$ within $0.09 \mathrm{~s}$ and changes in the longitudinal-vertical shear stress of about $0.003 \mathrm{~m}^{2} \mathrm{~s}^{-3}$ [Figure 7(e)], which correspond to changes with an amplitude of $u_{*}^{2}$ within $0.09 \mathrm{~s}$.

Hence, in line with Hart and Finelli (1999), Statzner (2008), Lancaster et al. (2006), Rice et al. (2008), and Long et al. (2011), our findings corroborate that benthic invertebrates are able to reduce the flow forcing due to small-scale local turbulence structures by hiding themselves in the less exposed zones of the streambed. However, our results indicate that they are less able to reduce exposure to the larger-scale coherent flow structures that are inherited from upstream interactions between the rough channel bed and the flow, which consequently are the dominant flow forcing with respect to invertebrate dislodgment. These results underpin our second hypothesis.

\section{DISCUSSION}

The results confirmed two hypotheses. (i) Invertebrates are not only sensitive to the peak values of the turbulent forcing by the flow but also to the temporal fluctuations in this turbulent flow forcing, i.e. the time required for the flow forcing to fluctuate between its average and peak values; This constitutes a fundamental difference with respect to the passive transport of sediment particles that is only sensitive to the peak values. (ii) The dominant temporal fluctuations are not due to small-scale turbulent structures of the size of the invertebrate body that are influenced by the interaction between the boundary layer and the invertebrate body, but to large-scale turbulent structures that scale with the flow depth and are inherited from upstream.

From an applied perspective, these results imply that predictive habitat models for invertebrate distribution, intending to reflect physical-biological coupling, should primarily quantify and parameterize two aspects: (i) local substrate heterogeneity and its hiding potential for streambed invertebrates; and (ii) peaks in flow forcing and the temporal fluctuations of flow related to the dominant turbulent coherent structures. Boyero (2003) has proposed a method to approach the former aspect on the basis of multiple metrics able to quantify two components of the substrate heterogeneity: the composition and the spatial configuration of substrate patches. The following discussion therefore focuses on the second aspect.

The order of magnitude of the temporal fluctuations associated with the turbulent peak values can be estimated from simplified hydrodynamic considerations. According to Laufer and Badri Narayan (1971), Rao et al. (1971) and Mignot et al. (2009), large-scale turbulent coherent structures are intermittently generated with a time interval that scales with $T \approx H / U$. Hence, it can reasonably be assumed that flow variables increase from their time-averaged value to their turbulent peak value in a time $T$. For the longitudinal-vertical shear stress, for example, this would yield an estimate of the temporal fluctuations of

$$
\frac{\Delta v_{x}^{\prime} v_{z}^{\prime}}{\Delta t}=\frac{3 u_{*}^{2}}{T} \approx 3 u_{*}^{2} \frac{U}{H}=3 C_{f} \frac{U^{3}}{H}
$$

where $C_{f}$ is a dimensionless Chézy-type friction coefficient. This relation indicates that the temporal fluctuations increase with increasing channel roughness and flow velocity, and decrease with increasing water depth. A more accurate quantification of the flow forcing can, at present, be obtained from so-called eddy-resolving hydrodynamic models (van Balen et al., 2010; Constantinescu et al., 2011; Kang and Sotiropoulos, 2011). These recently developed numerical models resolve directly the spatial-temporal patterns of the large turbulence structures, which allows for the quantification of the peak values and temporal fluctuations in velocity, shear stress, tke, as well as the identification of turbulent coherent structures based on the quadrant analysis.

Obviously, flow and turbulence parameters that are of dominant importance with respect to invertebrate dislodgement can only be identified by means of experiments. Therefore, experiments are essential for defining the parameters that need to be extracted from the eddy-resolving hydrodynamic models, and that subsequently can be used to build coupled hydro-ecological models. Hence, our results enable a new understanding of the detailed hydraulic conditions leading to passive drift of stream invertebrates, and thus open new perspectives to improve models predicting the distribution of benthic invertebrates based on hydrodynamics by accounting for turbulence. This constitutes an enhancement of currently used habitat models, such as 'CASIMIR' (Bratrich and Jorde, 1997) or 'PHABSIM' (Waddle, 2001), which at present only account for timeaveraged flow parameters. The reported methodology can be extended to investigate the role of turbulence on other key aspects for invertebrate spatial distribution, such as the drift trajectories following dislodgment or the ability of invertebrates to actively swim.

\section{ACKNOWLEDGEMENTS}

This research was sponsored by the Deutsche Forschungsgemeinschaft (DFG) and the Netherlands Organization for Scientific Research (NWO) under grants SU 405/3-1 and DN66-149, respectively, in the framework of their bilateral cooperation programme. The first author was partially funded by the Chinese Academy of Sciences Visiting Professorship for Senior International Scientists, grant number 2011T2Z24, and by the Sino-Swiss Science and Technology Cooperation for the Institutional Partnership, grant number IP13_092911. 


\section{REFERENCES}

Allan JD. 1995. Stream Ecology: Structure and Function of Running Waters. Chapman and Hall: London; 388.

Ambühl H. 1959. Die Bedeutung der Strömung als ökologischer Faktor. Schweizerische Zeitschrift für Hydrologie 21: 133-264.

Anasco NC, Koyama J, Imai S, Nakamura K. 2008. Toxicity of residual chlorines from hypochlorite-treated seawater to marine amphipod Hyale barbicornis and estuarine fish Oryzias javanicus. Water, Air, and Soil Pollution 195(1-4): 129-136.

Antonia RA, Atkinson JD. 1973. High-order moments of Reynolds shear stress fluctuations in a turbulent boundary layer. Journal of Fluid Mechanics 58(3): 581-593.

Ashworth P, Bennett S, Best JL, Lelland MC. 1996. Coherent Flow Structures in Open Channels. Wiley: Hoboken, N. J. ISBN 978-0-47195723-2.

Batchelor GK. 1970. An Introduction to Fluid Dynamics. Cambridge University Press: Cambridge.

Blanckaert K. 2010. Topographic steering, flow recirculation, velocity redistribution, and bed topography in sharp meander bends. Water Resources Research 46: W09506.

Blanckaert K, de Vriend HJ. 2004. Secondary flow in sharp open-channel bends. Journal of Fluid Mechanics 498: 353-380.

Blanckaert K, Graf WH. 2001. Experiments on flow in an open-channel bend. Mean flow and turbulence. Journal of Hydraulic Engineering, ASCE, 12710: 835-847.

Blanckaert K, Lemmin U. 2006. Means of noise reduction in acoustic turbulence measurements. Journal of Hydraulic Research, IAHR, 441: $3-17$.

Boyero L. 2003. 'The quantification of local substrate heterogeneity in streams and its significance for macroinvertebrate assemblages. Hydrobiologia 499: 161-168.

Bratrich C, Jorde K. 1997. Hydraulische und morphologische Modellierung von Fliessgewässern mit dem Simulationsmodell CASIMIR: Gewässerbiologie und Habitatmodellierung. Wasserwirtschaft 78: 370-371.

Cellio M, Lemmin U. 2004. Influence of coherent flow structures on the dynamics of suspended sediment transport in open-channel flow. Journal of Hydraulic Engineering 13011: 1077-1088. DOI: 10.1061/ASCE073394292004130:111077.

Chang WY, Constantinescu G, Tsai WF, Lien HC. 2012. Coherent structures dynamics and sediment erosion mechanisms around an instream rectangular cylinder at low and moderate angles of attack. Water Resources Research DOI: 10.1029/2011WR010586, in press.

Constantinescu G, Koken M, Zeng J. 2011. The structure of turbulent flow in an open channel bend of strong curvature with deformed bed: insight provided by detached eddy simulation. Water Resources Research 47: W05515. DOI: 10.1029/2010WR010114.

Dwivedi A, Melvill BW, Shamseldin AY, Guga TK. 2011. Flow structures and hydrodynamic force during sediment entrainment. Water Resources Research 47: W01509. DOI: 10.1029/2010WR009089

Eckman JE, Savidge WB, Gross TF. 1990. Relationship between duration of cyprid attachment and drag forces associated with detachment of Balanus amphitrite cyprids. Marine Biology 107: 111-118.

Einstein HA, Li H. 1958. The viscous sublayer along a smooth boundary. Transactions, ASCE, 123, Paper No. 2992, pp. 293-313.

Escauriaza C, Sotiropoulos F. 2011. Lagrangian model of bed-load transport in turbulent 799 junction flows. Journal of Fluid Mechanics 666: $36-76$.

Gibbins C, Vericat D, Batalla RJ. 2007. When is stream invertebrate drift catastrophic? The role of hydraulics and sediment transport in initiating drift during flood events. Freshwater Biology 52: 2369-2384

Gibbins C, Batalla RJ, Vericat D. 2010. Invertebrate drift and benthic exhaustion during disturbance: response of mayflies (Ephemeroptera) to increasing shear stress and river-bed instability. River Research and Applications 26: 499-511.

Grass AJ. 1971. Structural features of turbulent flow over smooth and rough boundaries. Journal of Fluid Mechanics 50: 233.

Hart DD, Finelli CM. 1999. Physical-biological coupling in streams: the pervasive effects of flow on benthic organisms. Annual Review of Ecological Systems 30: 363-395.

Hart DD, Clark BD, Jasentuliyana A. 1996. Fine-scale field measurement of benthic flow environments inhabited by stream invertebrates. Limnology and Oceanography 412: 297-308.

Hinze JO. 1959. Turbulence. McGraw-Hill: New York.

Hurther D, Lemmin U. 1998. A constant beam-width transducer for threedimensional Doppler profile measurements in open channel flow. Measurement Science \& Technology, IOP, 910: 1706-1714.
Hurther D, Lemmin U. 2003. Turbulent particle and momentum flux statistics in suspension flow. Water Resources Research 39(5). DOI: 10.1029/2001WR001113.

Hurther D, Lemmin U, Terray EA. 2007. Turbulent transport in the outer region of rough wall open-channel flows: the contribution of large coherent shear stress structures (LC3S). Journal of Fluid Mechanics 574: 465-493.

Hynes HBN. 1970. The Ecology of Running Waters. Univ. Liverpool Press: Liverpool, UK.

Janecek BFU, Moog O, Waringer J. 1995. Odonata. In Fauna Aquatica Austriaca, Lieferungen 1995, 2002, Moog O (ed). Bundesministerium fuer Land- und Forstwirtschaft, Umwelt und Wasserwirtschaft, Wasserwirtschaftskataster: Wien.

Jimenez J. 2004. Turbulent flows over rough walls. Annual Review of Fluid Mechanics 36: 173-196.

Kang S, Sotiropoulos F. 2011. Flow phenomena and mechanisms in a field-scale experimental meandering stream with a pool-riffle sequence: insight gained via numerical simulation. Journal of Geophysical Research 116: F03011. DOI: 10.1029/2010JF001814.

Kline SJ, Reynolds WC, Schraub FA, Runstadl PW. 1967. Structure of turbulent boundary layers. Journal of Fluid Mechanics 30: 741. DOI: 10.1017/S0022112067001740.

Koehl MAR. 1984. How do benthic organisms withstand moving water. American Zoologist 241: 57-70.

Koehl MAR. 1996. When does morphology matter ? Annual Review of Ecological Systems 27: 501-542.

Kolmogorov AN. 1961. The local structure of turbulence in incompressible viscous fluid for very large Reynolds numbers. English translation. In Turbulence Classic Papers on Statistical Theory, Friedlander SK, Topper L (eds). Interscience publ.: New York.

Lancaster J, Downes BJ. 2010. Linking the hydraulic world of individual organisms to ecological processes: putting ecology into ecohydraulics. River Research and Applications 264: 385-403. DOI: 10.1002/rra.1274.

Lancaster J, Buffin-Bélanger T, Reid I, Rice S. 2006. Flow- and substratum-mediated movement by a stream insect. Freshwater Biology 51: 1053-1069.

Laufer J, Badri Narayan MA. 1971. Mean period of turbulent production mechanism in a boundary layer. Physics of Fluids 141: 182. DOI: 10.1063/1.1693271.

Leite Ribeiro M, Blanckaert K, Roy AG, Schleiss AJ. 2012. Flow and sediment dynamics in channel confluences. Journal of Geophysical Research 117: F01035. DOI: 10.1029/2011JF002171.

Lemmin U, Rolland T. 1997. Acoustic velocity profiler for laboratory and field studies. Journal of Hydraulic Engineering, ASCE, 12312: 1089-1098.

Long A, Ashe W, Ravana K, Simon KS. 2011. The effect of water velocity and sediment size on Acroneuria abnormis (Plecoptera: Perlidae) entrainment. Aquatic Insects 332: 105-112.

Lu SS, Willmarth WW. 1973. Measurements of the structure of the Reynolds stress in a turbulent boundary layer. Journal of Fluid Mechanics 60: 481-511.

Mc Reid MA, Thoms MC. 2008. Surface flow types, near-bed hydraulics and the distribution of stream macroinvertebrates. Biogeosciences 5: 1043-1055.

Mignot E, Hurther D, Barhelemy E. 2009. On the structure of shear stress and turbulent kinetic energy flux across the roughness layer of a gravelbed channel flow. Journal of Fluid Mechanics 638: 423-452. DOI: 10.1017/S0022112009990772.

Nakagawa H, Nezu I. 1977. Prediction of the contribution to Reynolds stress from bursting events in open-channel flows. Journal of Fluid Mechanics 80(1): 99-128.

Nelson JM, Shreve RL, McLean SR, Drake TG. 1995. Role of near-bed turbulence structure in bed load transport and bed form mechanics. Water Resources Research 31: 2071-2086.

Nezu I, Nakagawa H. 1993. Turbulence in Open-Channel Flows, Balkema: Rotterdam, The Netherlands.

Nikora V, Goring D, McEwan I, Griffiths G. 2001. Spatially averaged open-channel flow over rough bed. Journal of Hydraulic Engineering 1272: 123-133. DOI: 10.1061/ASCE0733-94292001127:2123.

Oldmeadow DF, Lancaster J, Rice SP. 2010. Drift and settlement of stream insects in a complex hydraulic environment. Freshwater Biology 55(5): 1020-1035. DOI: 10.1111/j.1365-2427.2009.02338.x.

Prandtl L. 1930. Reprinted in L. Prandtl 1961. Gesammelte Abhandlungen zur angewandten Mechanik. In Hydro- und Aerodynamic collected works, Tollmien W, Schlichting H, Goertler H (eds). Springer-Verlag: New York.

Prandtl L. 1942. Führer durch die Strömungslehre. Vieweg: Braunschweig. Rao KN, Narasimha R, Bardi Narayan MA. 1971. The bursting phenomenon in a turbulent boundary layer. Journal of Fluid Mechanics 48: 339-352. 
Raupach MR, Antonia RA, Rajagopalan S. 1981. Conditional statistics of Reynolds stress in rough wall and smooth wall turbulent boundary layers Journal of Fluid Mechanics 108: 363-382.

Reid MA, Thoms MC. 2008. Surface flow types, near-bed hydraulics and the distribution of stream macroinvertebrates. Biogeosciences 5: 1043-1055.

Rice SP, Buffin-Bélanger T, Lancaster J, Reid I. 2008. Movements of macroinvertebrate Potamophylax latipennis across a gravel-bed substrate: effects of local hydraulics and micro-topography under increasing discharge. In Gravel-bed Rivers: From Process Understanding to River Restoration, Habersack H, Hoey T, Piegay H, Rinaldi M (eds). Elsevier BV: Amsterdam; 637-660.

Robert A. 1993. Bed configuration and microscale processes in alluvial channels. Progress in Physical Geography 121: 171-179.

Robinson SK. 1991. Coherent motions in the turbulent boundary layer. Annual Review of Fluid Mechanics 23: 601-639.

Schlichting H, Gersten K. 2000. Boundary-Layer Theory, 8th edn., Springer-Verlag: New York.

Schmedtje U, Colling M. 1996. Oekologische Typisierung der aquatischen Makrofauna. Informationsberichte des Bayerischen Landesamtes fuer Wasserwirtschaft 4/96, $543 \mathrm{pp}$

Schnauder I, Rudnick S, Garcia XF, Aberle J. 2010. Incipient motion and drift of benthic invertebrates in boundary shear layers. In River Flow 2010, Dittrich A, Koll K, Aberle J, Geisenhainer P (eds). Proc. of 5th Int. Conference on Fluvial Hyfraulics, September 7-10, 2010, Braunschweig, Germany.

Shields A. 1936. Anwendung der Aehnlichkeitsmechanik und der Turbulenzforschung auf die Geschiebebewegung [Application of similarity mechanics and turbulence research on shear flow]. Mitteilungen der Preußischen Versuchsanstalt für Wasserbau. 26. Berlin: Preußischen Versuchsanstalt für Wasserbau.

Statzner B. 2008. How views about flow adaptations of benthic stream invertebrates changed over the last century. International Review of Hydrobiology 93(4-5): 593-605.
Statzner B, Higler B. 1986. Stream hydraulics as a major determinant of benthic invertebrate zonation patterns. Freshwater Biology 16: 127-139.

Statzner B, Holm TF. 1982. Morphological adaptations of benthic invertebrates to stream flow - an old question studied by means of a new technique (Laser Doppler Anemometry). Oecologia 53: 290-292.

Statzner B, Holm TF. 1989. Morphological adaptation of shape to flow: microcurrents around lotic macroinvertebrates with known Reynolds numbers at quasi-natural flow conditions. Oecologia 78: 145-157.

Statzner B, Gore JA, Resh VH. 1988. Hydraulic stream ecology: observed patterns and potential applications. Journal of the North American Benthological Society 7: 307-360.

Sutherland AJ. 1967. Proposed mechanism for sediment entrainment by turbulent flows. Journal of Geophysical Research 7224: 6183-6194. DOI: 10.1029/JZ072i024p06183.

Taylor GI. 1938. The spectrum of turbulence. Proc. R. Soc. London A 164: 476

Van Balen W, Uijttewaal WSJ, Blanckaert K. 2010. Large-eddy simulation of a curved open-channel flow over topography. Physics of Fluids 22: 075108. DOI: 10.1063/1.3459152.

Van Prooijen BC, Winterwerp JC. 2010. A stochastic formulation for erosion of cohesive sediments. Journal of Geophysical Research Oceans 115: C01005. DOI: 10.1029/2008JC005189.

Van Rijn LC. 1984. Sediment transport, part III: bed forms and alluvial roughness. Journal of Hydraulic Engineering, ASCE, 11012: 1733-1754.

Vogel S. 1994. Life in Moving Fluids: The Physical Biology of Flow, 2nd edn. Princeton University Press: Princeton.

Waddle TJ. 2001. PHABSIM for Windows User's Manual and Exercises. U.S. Geological Survey Open-File Report 2001-340.

Weissenberger J, Spatz HC, Emanns A, Schwoerbel J. 1991. Measurement of lift and drag forces in the $\mathrm{mN}$ range experienced by benthic arthropods at flow velocities below $1.2 \mathrm{~m} \mathrm{~s}^{-1}$. Freshwater Biology 25: 21-31. 